\title{
Dampak Reverse Stock Split terhadap Nilai Perusahaan yang Terdaftar di Bursa Efek Indonesia.
}

\author{
Evelin Budiarti ${ }^{1}$ \\ Fakultas Ekonomi dan Bisnis \\ Universitas Udayana, Indonesia. \\ Email: evelinbudiarti@yahoo.co.id
}

\author{
Ida Bagus Putra Astika² \\ Fakultas Ekonomi dan Bisnis \\ Universitas Udayana, Indonesia.
}

\begin{abstract}
ABSTRAK
Memaksimumkan nilai perusahaan menjadi salah satu tujuan perusahaan dalam menjalankan bisnisnya. Nilai perusahaan sering dikaitkan dengan harga saham. Besarnya harga saham dapat berubah-ubah karena permintaan dan penawaran yang ada di pasar. Investor mempertimbangkan beberapa faktor dalam pengambilan keputusan investasinya, seperti informasi aksi korporasi. Reverse stock split merupakan salah satu bentuk dari aksi korporasi. Tujuan dari penelitian ini adalah mendapatkan bukti empiris mengenai perbedaan nilai perusahaan sebelum dan sesudah dilakukan reverse stock split. Penelitian ini dilakukan pada perusahaan yang terdaftar di Bursa Efek Indonesia pada tahun 2009-2018. Sampel dipilih menggunakan metode purposive sampling sehingga diperoleh sebanyak 15 perusahaan. Teknik analisis data yang digunakan adalah dengan uji beda, yaitu uji Wilcoxon. Penelitian ini menunjukan bahwa tidak terdapat perbedaan nilai perusahaan antara sebelum dan sesudah dilakukan reverse stock split.
\end{abstract}

Kata Kunci :

Reverse Stock Split; Stock Split Down; Penggabungan Saham; Nilai Perusahaan.

\section{The Impact of Reverse Stock Split to Indonesian Stock Exchange's Firms Value}

\begin{abstract}
Maximizing the firms value is one of the company's goals in running its business. The value of a company is often affected by the share price. The stock price itself changes because of the demand and supply in the market. In making investment decisions, investors consider several factors, such as information of corporate actions. Reverse stock split is one type of corporate action. The purpose of this study is to obtain empirical evidence regarding differences of firms value before and after reverse stock split. This research was conducted at companies published on the Indonesia Stock Exchange in 2009-2018. Samples were selected using purposive sampling method so as many as 15 companies were obtained. The data analysis technique used in this study was the Wilcoxon test. The results of this study indicate there is no difference of firms value between before and after a reverse stock split.
\end{abstract}

Keywords: $\quad$ Reverse Stock Split; Stock Split Down; Firms Value.

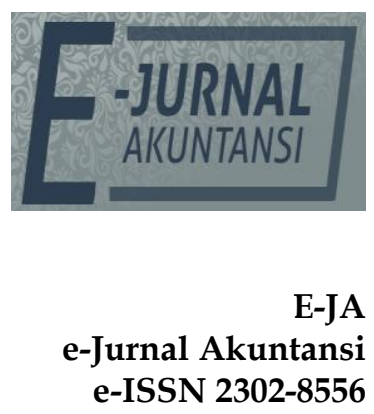

Vol. 29 No. 3

Denpasar, Desember

2019

Hal. 1094-1105

Artikel masuk: 24 September 2019

Tanggal diterima: 22 Desember 2019 


\section{PENDAHULUAN}

Theory of the firm menganggap bahwa yang menjadi tujuan utama perusahaan adalah memaksimumkan nilai perusahaan (Kontesa, 2015). Sering kali nilai perusahaan dikaitkan dengan harga saham, di mana saham dengan harga yang tinggi akan membuat nilai perusahaan menjadi tinggi pula. Terlalu rendahnya harga saham sering dianggap berarti perusahaan memiliki kinerja yang kurang baik, akan tetapi harga saham yang terlalu tinggi akan membuat minat untuk berinvestasi yang dimiliki oleh investor menjadi berkurang (Widiastuti, 2005). Harga saham yang rendah terkadang menjadi alasan kurang tertariknya seorang investor menanamkan modalnya, sehingga perusahaan harus dapat mempertahankan harga sahamnya di range harga yang dapat dijangkau oleh pasar.

Menyediakan informasi kepada publik menjadi penting bagi perusahaan untuk mempertahankan harga sahamnya. Beberapa perusahaan yang diberikan kebebasan dalam sistem pengungkapan laporan keuangan secara wajib dan memilih untuk tidak mengikuti sistem pengungkapan wajib tersebut, menjadi terpuruk karena menyediakan informasi yang lebih sedikit kepada investor publik (Fried, 2009). Dengan menyediakan informasi, maka para pemegang saham dapat lebih mudah dalam membuat keputusan. Apabila suatu informasi dianggap relevan oleh para investor, investor akan menggunakannya untuk dianalisis dan diinterpretasi mengenai nilai saham perusahaan tersebut (Fidhayatin \& Uswati Dewi, 2012). Salah satu informasi penting yang ada di pasar modal adalah aksi korporasi (corporate action). Tujuan perusahan melakukan aksi korporasi adalah untuk meningkatkan kinerja perusahaan baik itu dalam jangka panjang maupun jangka pendek.

Reverse stock split merupakan salah satu jenis dari aksi korporasi. Reverse stock split hanya meningkatkan nilai nominalnya, dimana nilai nominal yang berubah tersebut hanya menyebabkan penurunan jumlah lembar saham dan tidak mengubah jumlah modal. Vafeas (2001) mengemukakan bahwa reverse stock split secara mendasar adalah paper transaction, reverse stock split tidak menyebabkan aliran kas dari perusahaan secara langsung dan tidak mengubah kepemilikan para pemegang saham secara proporsional. Reverse stock split merupakan keputusan penting bagi sebuah perusahaan, sehingga tidak bisa langsung dilakukan begitu saja. Reverse stock split dapat dilakukan oleh perusahaan apabila usulan untuk melakukan reverse stock split yang sudah disetujui saat RUPS/ RUPSLB disetujui pula oleh Bursa Efek Indonesia (BEI). Perusahaan yang melakukan reverse stock split tidak perlu mencatatnya di jurnal, akan tetapi biasanya akan dicatat di catatan atas laporan keuangan. Perusahaan yang melakukan reverse stock split harus melakukan penyesuaian secara retrospektif dan laporan keuangannya akan disajikan kembali (restatement), hal ini dikarenakan reverse stock split mempengaruhi jumlah saham yang beredar dan akan mengubah jumlah laba per saham. Paragraf 64 PSAK 56 tentang Laba Per Saham menjelaskan bahwa jika jumlah saham biasa menurun sebagai akibat dari reverse stock split, maka penghitungan laba per saham dasar dan dilusian untuk seluruh periode yang disajikan disesuaikan secara retrospektif. Selain itu, dikarenakan pentingnya informasi reverse stock split, maka informasi tersebut harus diungkapkan pada laporan tahunan. Pasal 6 Peraturan Otoritas Jasa 
Keuangan Nomor 29/POJK.04/2016 tentang Laporan Tahunan Emiten atau Perusahaan Publik menjelaskan bahwa dalam hal terjadi aksi korporasi, seperti pemecahan saham (stock split), penggabungan saham (reverse stock), dividen saham, saham bonus, dan perubahan nilai nominal saham, perusahaan wajib secara paling sedikit menjelaskan pada laporan tahunan mengenai tanggal pelaksanaan, rasio, jumlah saham beredar sebelum dan sesudah aksi korporasi, dan harga saham sebelum dan sesudah aksi korporasi.

Pada umumnya, reverse stock split dianggap sebagai sinyal negatif. Biasanya, perusahaan yang melakukan reverse stock split merupakan perusahaan dengan kinerja saham yang buruk sebelumnya dan merupakan perusahaan yang sangat tidak menguntungkan (Neuhauser \& Thompson, 2014). Perusahaan yang melakukan reverse stock split akhirnya lebih banyak yang dilikuidasi atau didelisting dari bursa (Crutchley \& Swidler, 2015). Akan tetapi, tidak menutup kemungkinan bisa saja terjadi sebaliknya, dengan reverse stock split maka akan menimbulkan sinyal postif bagi pasar. Harga saham diharapkan dapat berubah ke range yang lebih menarik setelah dilakukannya reverse stock split (Fitria et al., 2019), sehingga investor lebih tertarik untuk melakukan transaksi dan nilai perusahaan dapat meningkat.

Sebelumnya, sudah ada beberapa penelitian mengenai reverse stock split yang berkaitan dengan reaksi pasar, apabila pasar memberikan reaksi akan berdampak pada harga saham dan dapat mempengaruhi nilai perusahaan itu sendiri. Akan tetapi, hasil penelitian sebelumnya masih kurang konsisten, di mana pada penelitian yang dilakukan oleh Dewi (2011) menunjukan hasil bahwa terdapat perbedaan volume perdagangan saham antara sebelum dan sesudah peristiwa reverse stock split, yaitu adanya peningkatan, sehingga dianggap dapat memberi sinyal yang positif. Sejalan dengan hasil dari penelitian yang dilakukan oleh Masse, et al. (2017) di mana reverse stock split memberikan sinyal positif. Penelitian oleh Fransiska \& Purwaningsih (2008) menunjukkan bahwa terjadi peningkatan nilai rata-rata trading volume activity antara sebelum dengan sesudah peristiwa reverse stock split. Sedangkan, penelitian Adnyani \& Putri (2014) menemukan hasil bahwa terdapat perbedaan abnormal return sebelum dan sesudah reverse stock split yaitu terjadi penurunan sesudah dilakukannya reverse stock split.

Penelitian oleh Kusdarmawan \& Abundanti (2018) memperoleh hasil bahwa antara abnormal return saham sebelum dan sesudah pengumuman reverse stock split tidak ditemukan adanya perbedaan yang signifikan. Hal tersebut memiliki arti bahwa adanya reverse stock split tidak direspon oleh pasar dikarenakan investor menganggap reverse stock split tidak mengandung informasi yang penting. Selain itu, penelitian yang dilakukan oleh Mardiyati \& Khasanah (2011) menunjukan bahwa harga saham tidak berbeda antara periode sebelum aksi reverse stock split dan sesudah aksi reverse stock split.

Tujuan penelitian ini adalah untuk mendapatkan bukti empiris mengenai perbedaan nilai perusahaan sebelum dan sesudah dilakukan reverse stock split. Teori dan konsep yang digunakan dalam penelitian ini adalah teori sinyal, reverse stock split, dan nilai perusahaan. Teori sinyal menggambarkan bahwa informasi yang dikeluarkan perusahaan yang sampai ke publik dapat menimbulkan penilaian oleh publik, apakah informasi tersebut merupakan good news atau bad 
news. Sinyal yang berasal dari perusahaan yang kondisi fundamentalnya terpercaya akan direspon oleh investor sehingga sinyal tersebut menjadi berkualitas, sedangkan sinyal yang berasal dari perusahaan yang kondisi fundamentalnya kurang terpercaya maka kurang dapat menyamai sinyal yang berasal dari perusahaan yang kondisi fundamentalnya lebih terpercaya (Bhattacharya \& Dittmar, 2005). Saat informasi direspon, maka investor akan bereaksi dengan menjual, menahan, atau membeli lagi saham tersebut. Reaksi pasar tersebut dapat tercermin melalui perubahan harga saham yang terjadi di pasar (Adnyani \& Putri, 2014).

Aksi reverse stock split adalah aktivitas penggabungan beberapa lembar saham menjadi satu lembar saham sehingga lembar saham yang beredar menjadi lebih sedikit dan harga per sahamnya menjadi lebih tinggi (Ahn et al., 2015). Reverse stock split adalah aktivitas yang dilakukan oleh perusahaan terbuka yang harga sahamnya lebih rendah daripada yang ditargetkan, dengan reverse stock split perusahaan mencoba untuk meningkatkan harga pada tingkat tertentu (Bajra \& Hasani, 2012). Manajemen berharap, dengan melakukan reverse stock split maka harga saham akan berada pada kisaran optimal trading range (Bodhanwala, 2016). Penelitian yang dilakukan oleh Jing (2003) menjelaskan mengenai hal yang menjadi alasan utama perusahaan melakukan reverse stock split, yaitu: reverse stock split dapat mengurangi biaya transaksi karena jumlah lembar saham yang beredar akan berkurang, reverse stock split dapat memperbaiki fleksibilitas harga saham yang baru ketika dibutuhkan, reverse stock split dapat meningkatkan laba perusahaan di mata investor, dan reverse stock split dapat memulihkan harga saham pada tingkat yang semakin optimal dan menjadi lebih menarik untuk diperdagangkan.

Nilai perusahaan sering dikaitkan dengan harga saham, di mana harga saham yang tinggi membuat nilai perusahaan juga tinggi. Terdapat beberapa proksi yang bisa digunakan dalam mengukur nilai perusahaan, yaitu price earning ratio (PER), price to book value (PBV), dan Tobin's Q (Panggabean \& Prasetiono, 2017). PER merupakan rasio yang mengukur harga saham perusahaan saat ini terhadap laba per saham perusahaan, sedangkan PBV berfungsi untuk mengukur nilai perusahaan dengan membandingkan rasio pasar yang digunakan dalam mengukur kinerja harga pasar saham per lembar terhadap nilai buku saham per lembarnya. Sementara itu, Tobin's Q merupakan indikator yang berfungsi dalam mengukur kinerja suatu perusahaan, secara khusus nilai suatu perusahaan yang menunjukan pula kemampuan manajemen dalam mengelola aset perusahaan.

Berdasarkan teori sinyal, reverse stock split akan memberikan informasi kepada pasar dan mengakibatkan pasar bereaksi terhadap kejadian tersebut. Teori sinyal memandang bahwa manajemen dapat mempengaruhi persepsi investor terhadap perusahaan mereka dengan mengubah harga saham (Marchman, 2007). Investor yang mengetahui informasi tentang reverse stock split tersebut akan memberikan reaksi dengan membeli atau menjual saham perusahaan tersebut. Dengan adanya reaksi pasar, maka akan mengubah volume perdagangan saham dan harga saham dari perusahaan yang melakukan reverse stock split. Harga saham tergantung pada permintaan dan penawaran saham dan harga saham mencerminkan nilai perusahaan. Apabila suatu perusahaan 
memiliki suatu prestasi yang baik, maka saham tersebut akan diminati oleh investor. Sehingga hal tersebut memungkinkan terjadinya perubahan nilai perusahaan.

Ratmawati \& Kusumawati (2007) menyatakan bahwa reverse stock split masih relevan untuk menjaga kepercayaan investor. Dengan demikian, dengan adanya reverse stock split maka akan menjadi sinyal bagi investor bahwa perusahaan tersebut dapat dipercaya, sehingga akan menimbulkan minat investor untuk membeli saham tersebut. Adanya peningkatan pembelian saham, akan semakin meningkatkan harga saham tersebut dan meningkatkan nilai perusahaan pula. Penelitian yang dilakukan oleh Sanjaya (2007) memperoleh hasil bahwa pasar memberika reaksi terhadap pengumuman reverse stock split, hal ini berarti reverse stock split memiliki kandungan informasi. Penelitian yang dilakukan oleh gan saham sebelum dan sesudah peristiwa reverse stock split, yaitu mengalami peningkatan, sehingga reverse stock split dapat memberi sinyal yang positif. Penelitian oleh Fransiska \& Purwaningsih (2008) menunjukkan bahwa terjadi peningkatan nilai rata-rata trading volume activity antara sebelum dengan sesudah peristiwa reverse stock split. Selain itu, penelitian yang dilakukan oleh Adnyani \& Putri (2014) menemukan hasil bahwa terdapat perbedaan abnormal return sebelum dan sesudah peristiwa reverse stock split yaitu terjadi penurunan sesudah peristiwa reverse stock split.

Penelitian-penelitian tersebut menghitung trading volume activity berdasarkan banyaknya volume saham yang diperdagangkan, semakin banyak volume saham yang diperdagangkan maka harga saham akan semakin meningkat, begitupula sebaliknya jika volume saham yang diperdagangkan semakin sedikit maka harga saham akan semakin menurun. Sedangkan pada rata-rata return saham maupun nilai abnormal return diproksikan dengan harga saham. Harga saham akan mencerminkan nilai perusahaan, sehingga dengan demikian hal tersebut dapat mempengaruhi nilai perusahaan. Berdasarkan rumusan masalah, tujuan penelitian, teori, dan hasil penelitian-penelitian sebelumnya, maka hipotesis dalam penelitian ini dapat dirumuskan sebagai berikut:

$\mathrm{H}_{1}$ : Terdapat perbedaan nilai perusahaan sebelum dan sesudah perusahaan melakukan reverse stock split.

\section{METODE PENELITIAN}

Penelitian ini merupakan penelitian kuantitatif dengan bentuk komparatif. Penelitian ini menggunakan data sekunder, di mana data diperoleh melalui pengumpulan data dengan cara mencatat, menganalisis, dan memperlajari buku, jurnal, serta laporan tahunan yang diakses melalui website Bursa Efek Indonesia (www.idx.co.id), www.morningstar.com, dan www.idnfinancials.com. Metode untuk mengumpulkan data adalah dengan menggunakan metode observasi nonpartisipan (nonparticipant observation). Objek yang diteliti adalah nilai perusahaan yang melakukan kebijakan reverse stock split. Penelitian ini mengambil populasi dari seluruh perusahaan yang terdaftar di Bursa Efek Indonesia selama periode 2009-2018. Teknik pengambilan sampel dilakukan dengan teknik nonprobability sampling dengan metode purposive sampling. Pertimbangan yang digunakan yaitu sampel merupakan perusahaan yang 
melakukan reverse stock split antara tahun 2009-2018. Sehingga diperoleh sampel sebanyak 15 perusahaan. Adapun variabel yang digunakan adalah nilai perusahaan.

Nilai perusahaan merupakan persepsi yang dimiliki oleh investor terhadap perusahaan yang umumnya terkait dengan harga saham perusahaan tersebut (Putu et al., 2014). Salah satu cara untuk mengukur nilai perusahaan adalah dengan menggunakan rasio Tobin's Q. Marsha \& Murtaqi (2017) menyatakan bahwa perusahaan dengan Tobin's $Q$ lebih besar dari 1 berarti telah menggunakan sumber daya perusahaan secara efektif, sedangkan dengan nilai kurang dari 1 berarti adanya penggunaan yang buruk atau tidak efisien atas sumber daya perusahaan.

Perhitungan nilai perusahaan dalam penelitian ini merupakan rumus Tobin's Q yang dikembangkan oleh Chung \& Pruitt (1944) dengan model yang lebih sederhana. Dimana biaya penggantian aset dengan nilai buku aset disamakan karena biaya penggantian aset sering kali tidak tersedia dan sulit diperhitungkan. Selanjutnya rumus tersebut juga disesuaikan dengan kondisi keuangan perusahaan di Indonesia dengan tidak menyertakan liquidating value of firm's outstanding preferred stock karena pada umumnya perusahaan yang terdaftar di Bursa Efek Indonesia tidak menerbitkan saham preferen. Sehingga, rumus Tobin's $Q$ yang digunakan dalam penelitian ini dirujuk dari penelitian Sudiyatno (2010) yang dirumuskaan sebagai berikut:

$\mathrm{Q}=\frac{\mathrm{MVS}+\mathrm{D}}{\mathrm{TA}}$

Keterangan:

Q : Nilai perusahaan

MVS : Market value of all outstanding shares (closing price akhir tahun $\mathrm{x}$ jumlah saham beredar akhir tahun)

TA : Total aktiva

D : Debt (liabilitas jangka pendek + liabilitas jangka panjang)

Market value of all outstanding shares (MVS) yang dihitung merupakan MVS pada akhir tahun sebelum perusahaan melakukan reverse stock split dan juga MVS pada akhir tahun setelah perusahaan melakukan reverse stock split. Penelitian ini menggunakan teknik analisis data dengan menggunakan uji beda. Analisis data dilakukan dengan bantuan program SPSS yang sebelumnya dilakukan analisis statistik deskriptif dan normalitas terlebih dahulu.

\section{HASIL DAN PEMBAHASAN}

Statistik deskriptif menjelaskan mengenai nilai minimum, nilai maksimum, nilai rata-rata, dan deviasi standar dari variabel-variabel penelitian.

Tabel 1. Hasil Statistik Deskripstif

\begin{tabular}{cccccc}
\hline & N & Minimum & Maksimum & $\begin{array}{c}\text { Rata- } \\
\text { rata }\end{array}$ & $\begin{array}{c}\text { Deviasi } \\
\text { Standar }\end{array}$ \\
\hline Sebelum & 15 & 0,72 & 2,76 & 1,35 & 0,58 \\
Sesudah & 15 & 0,48 & 2,91 & 1,24 & 0,76 \\
\hline
\end{tabular}

Sumber: Data Penelitian, 2019

Berdasarkan hasil statistik deskriptif pada Tabel 1 dapat dijelaskan bahwa sebelum perusahaan melakukan reverse stock split, rata-rata nilai perusahaan (Tobin's Q) adalah sebesar 1,35 dengan deviasi standar sebesar 0,58. PT Sierad 
Produce, Tbk. (SIPD) pada tahun 2014, sebelum melakukan reverse stock split memiliki nilai perusahaan terendah sebesar 0,72, sedangkan nilai perusahaan tertinggi sebesar 2,76 dimiliki oleh PT Kertas Basuki Rachmat Indonesia, Tbk. (KBRI) pada tahun 2009, sebelum perusahaan tersebut melakukan reverse stock split. Selain itu, rata-rata nilai perusahaan setelah perusahaan melakukan reverse stock split sebesar 1,24 dengan deviasi standar sebesar 0,76. Perusahaan PT Lippo Securities, Tbk. pada tahun 2011, sebelum melakukan reverse stock split memiliki nilai perusahaan terendah sebesar 0,48 , sedangkan nilai perusahaan tertinggi sebesar 2,91 dimiliki oleh PT. Samindo Resources, Tbk. (MYOH) sebelum perusahaan tersebut melakukan reverse stock split, yaitu pada tahun 2011.

Setelah dilakukan statistika deskriptif, dilakukan uji normalitas untuk mengetahui normalitas distribusi data penelitian. Jika data memiliki nilai Asymp. Sig (2-tailed) $>0,05$ maka dapat dikatakan bahwa data tersebut berdistribusi normal, begitu pula sebaliknya. Uji normalitas pada penelitian ini dilakukan dengan Uji Kolmogorovsmirnov. Tabel 2 berikut ini menunjukan hasil dari uji normalitas.

Tabel 2. Hasil Uji Normalitias

\begin{tabular}{llrr}
\hline & & Sebelum & \multicolumn{2}{c}{ Sesudah } \\
\hline $\mathrm{N}$ & & 15 & 15 \\
Parameter Normal & Rata-rata & 1,35 & 1,24 \\
& Deviasi Standar & 0,58 & 0,76 \\
Most Extreme Differences & Absolut & 0,22 & 0,33 \\
& Positif & 0,22 & 0,33 \\
& Negatif & $-0,14$ & $-0,16$ \\
Test Statistic & & 0,22 & 0,33 \\
Asymp. Sig. (2-tailed) & & 0,06 & 0,00 \\
\hline
\end{tabular}

Sumber: Data Penelitian, 2019

Pada Tabel 2 dapat dilihat bahwa nilai Asymp. Sig (2-tailed) pada nilai Tobin's $Q$ sebelum melakukan reverse stock split lebih besar dari 0,05, yaitu sebesar 0,06 $(0,06>0,05)$ yang berarti data berdistribusi normal, sedangkan Asymp sig (2-tailed) pada nilai Tobin's $Q$ sesudah melakukan reverse stock split lebih kecil dari 0,05, yaitu sebesar 0,00 $(0,00<0,05)$ yang berarti data berdistribusi tidak normal. Dapat kita lihat bahwa salah satu data berdistribusi secara tidak normal, oleh karena itu penelitian ini menggunakan uji statistik non-parametrik, yaitu Uji Wilcoxon.

Uji Wilcoxon merupakan uji yang didasarkan atas dasar rangking dan sangat bermanfaat apabila data yang digunakan merupakan data yang berskala ordinal. Tabel 3 berikut ini menunjukan hasil uji beda dengan Uji Wilcoxon.

\section{Tabel 3. Hasil Uji Beda}

\begin{tabular}{llcc}
\hline & & N & Signifikansi \\
\hline Sesudah - Sebelum & Rank Negatif & 9 & \\
& Rank Positif & 6 & \\
& Ties & 0 & \\
Total & 15 & 0,49 \\
& Asymp. Sig (2-Tailed) & & 0,4 \\
\hline
\end{tabular}

Sumber: Data Penelitian, 2019

Berdasarkan Tabel 3 dapat diketahui perbandingan nilai perusahaan antara sebelum dan sesudah perusahaan melakukan reverse stock split. Terdapat 9 
perusahaan dengan nilai perusahaan sesudah melakukan reverse stock split lebih rendah jika dibandingkan dengan sebelum perusahaan melakukan reverse stock split dan terdapat 6 perusahaan dengan nilai perusahaan sesudah melakukan reverse stock split lebih tinggi dibandingkan dengan sebelum perusahaan melakukan reverse stock split. Selain itu, dapat dilihat pula bahwa berdasarkan hasil tersebut, nilai Asymp. Sig (2-tailed) adalah sebesar 0,49. Hal tersebut menunjukan bahwa nilai Asymp. Sig (2-tailed) lebih besar dari 0,05 maka $\mathrm{H}_{0}$ diterima, yang berarti bahwa tidak ada perbedaan nilai perusahaan sebelum dan sesudah perusahaan melakukan reverse stock split.

Dapat kita lihat pada Tabel 1, rata-rata nilai Tobin's $Q$ sebelum dilakukan reverse stock split sebesar 1,35 , ternyata tidak memiliki perbedaan signifikan dengan nilai Tobin's Q setelah melakukan reverse stock split, yaitu sebesar 1,24. Hal ini dapat membuktikan bahwa tidak terdapat perbedaan nilai perusahaan antara sebelum dan sesudah perusahaan melakukan reverse stock split. Selain itu dapat diartikan pula bahwa reverse stock split dalam penelitian ini tidak memiliki kandungan informasi. Berdasarkan teori sinyal, dapat dikatakan bahwa tidak adanya nilai sinyal dalam reverse stock split yang dapat mengubah nilai perusahaan, reverse stock split dianggap tidak mengandung nilai informasi oleh para investor. Investor yang mengetahui informasi tentang reverse stock split tidak memberikan reaksi apapun sehingga tidak menimbulkan adanya reaksi pasar dan tidak mengubah harga saham dari perusahaan yang melakukan reverse stock split, sehingga nilai perusahaan juga tidak berubah.

Hasil penelitian ini sesuai dengan penelitian yang pernah dilakukan oleh Kusdarmawan \& Abundanti (2018) tidak menemukan adanya perbedaan signifikan pada abnormal return saham sebelum dan sesudah pengumuman reverse stock split, sehingga hal tersebut berarti pasar tidak merespon adanya reverse stock split karena reverse stock split tidak memiliki kandungan informasi dan tidak dianggap sebagai informasi yang penting bagi investor. Selain itu hasil penelitian ini juga sejalan dengan penelitian yang dilakukan oleh Mardiyati \& Khasanah (2011) yang menemukan bahwa antara sebelum dan sesudah perusahaan melakukan reverse stock split tidak terdapat perbedaan harga saham dan risiko saham. Hasil tersebut membuktikan bahwa reverse stock split tidak memiliki kandungan informasi. Penelitian yang dilakukan oleh Oktavia (2019) juga menunjukan tidak adanya perbedaan yang mempengaruhi abnormal return dan likuiditas perdagangan saham sebelum melakukan aksi reverse stock split dengan sesudah melakukan aksi reverse stock split, hal ini menandakan bahwa pengumuman aksi reverse stock split tidak memberikan sinyal dan informasi yang dapat menimbulkan reaksi pasar. Penelitian Jog \& Zhu (2004) juga menemukan bahwa dalam peristiwa reverse stock split tidak ditemukan adanya sinyal.

Hasil ini berbeda dengan hasil penelitian yang dilakukan oleh Sanjaya (2007) yang memperoleh hasil bahwa pasar memberikan reaksi terhadap pengumuman reverse stock split, hal ini berarti reverse stock split memiliki kandungan informasi. Demikian pula dengan penelitian yang dilakukan oleh Dewi (2011) menunjukan hasil bahwa terdapat perbedaan volume perdagangan saham sebelum dan sesudah peristiwa reverse stock split, yaitu mengalami peningkatan, sehingga reverse stock split dapat memberi sinyal yang positif. Penelitian oleh Fransiska \& Purwaningsih (2008) menunjukkan bahwa terjadi 
peningkatan nilai rata-rata trading volume activity antara sebelum dengan sesudah peristiwa reverse stock split. Selain itu, penelitian yang dilakukan oleh Adnyani \& Putri (2014) menemukan hasil bahwa terdapat perbedaan abnormal return sebelum dan sesudah peristiwa reverse stock split yaitu terjadi penurunan sesudah peristiwa reverse stock split. Pada penelitian-penelitian tersebut ditemukan bahwa reverse stock split memberikan sinyal kepada pasar, baik itu berupa sinyal positif maupun sinyal negatif. Adanya perbedaan dari hasil penelitian tersebut dapat dikarenakan sampel yang masih terbatas sehingga sulit untuk digeneralisasikan dan penelitian ini hanya meneliti nilai perusahaan pada akhir tahun sebelum dan sesudah perusahaan melakukan reverse stock split, sehingga terdapat kemungkinan bahwa pasar telah bereaksi ketika mendengar berita mengenai rencara perusahaan melakukan reverse stock split ataupun pada saat reverse stock split disetujui dalam RUPS, di mana berita tersebut sudah ada pada tahun sebelum aksi reverse stock split dilaksanakan, sehingga pasar sudah bereaksi pada tahun tersebut dan tidak bereaksi kembali pada tahun di mana reverse stock split dilaksanakan. Selain itu, perusahaan-perusahaan yang diteliti pada penelitian ini kebanyakan merupakan perusahaan-perusahaan yang melakukan reverse stock split dengan split ratio yang kecil, sehingga terdapat kemungkinan bahwa investor kurang tertarik dengan rasio dan peristiwa reverse stock split tersebut yang membuat harga saham tidak berubah dan juga tidak mengubah nilai perusahaan.

Sebagai implikasi teoritis, hasil penelitian ini memberikan bukti empiris bahwa tidak ada perbedaan nilai perusahaan sebelum dan sesudah dilakukan reverse stock split, hal ini berarti reverse stock split tidak memberikan dampak pada nilai perusahaan. Selain ini penelitian ini juga menunjukan hal yang bertentangan dengan teori sinyal, penelitian ini memberikan informasi bahwa reverse stock split tidak menimbulkan sinyal terhadap pasar, di mana investor menganggap reverse stock split tidak memiliki kandungan informasi yang penting. Selain itu, penelitian ini juga dapat dijadikan sebagai referesi serta perbandingan pengembangan maupun penyempurnaan dari penelitian yang telah ada terlebih dahulu. Sebagai implikasi praktis, hasil penelitian ini dapat menjadi pertimbangan bagi perusahaan ketika ingin melakukan reverse stock split. Penelitian ini juga dapat memberikan impilkasi bagi para pemegang saham sebagai tambahan informasi sebelum membuat keputusan, terutama mengenai reverse stock split.

\section{SIMPULAN}

Dilihat dari hasil analisis dan pembahasan yang telah dilakukan, maka dapat disimpulkan bahwa tidak terdapat perbedaan nilai perusahaan sebelum dan sesudah dilakukannya reverse stock split. Hal ini juga dapat diartikan bahwa reverse stock split tidak memiliki kandungan informasi yang penting bagi investor sehingga tidak menimbulkan reaksi terhadap pasar dan tidak mengubah nilai perusahaan.

Penelitian ini hanya meneliti nilai perusahaan pada akhir tahun sebelum dan sesudah perusahaan melakukan reverse stock split, sehingga terdapat kemungkinan bahwa pasar telah bereaksi ketika mendengar berita mengenai rencara perusahaan melakukan reverse stock split ataupun pada saat reverse stock 
split disetujui dalam RUPS, di mana berita tersebut sudah ada pada tahun sebelum aksi reverse stock split dilaksanakan, sehingga pasar sudah bereaksi pada tahun tersebut dan tidak bereaksi kembali pada tahun di mana reverse stock split dilaksanakan. Perusahaan-perusahaan yang diteliti pada penelitian ini kebanyakan merupakan perusahaan-perusahaan yang melakukan reverse stock split dengan split ratio yang kecil, sehingga terdapat kemungkinan bahwa investor kurang tertarik dengan rasio dan peristiwa reverse stock split tersebut yang membuat harga saham tidak berubah dan juga tidak mengubah nilai perusahaan.

Bagi investor disarankan agar tidak mengambil keputusan berdasarkan informasi reverse stock split saja, melainkan melihat pula dari informasi-informasi lain yang ada; bagi peneliti selanjutnya disarankan untuk meneliti pada saat perusahaan mengumumkan akan dilakukannya reverse stock split atau paa saat reverse stock split disetujui di RUPS dan agar menambahkan faktor-faktor lain yang mungkin dapat mempengaruhi nilai perusahaan yang melakukan reverse stock split, seperti split ratio. Peneliti selanjutnya juga disaranakan untuk melakukan penelitian dengan menambahkan proksi nilai perusahaan lainnya, sehingga dapat dibandingkan antara satu proksi dengan proksi lainnya., disarankan untuk berusaha agar terhindar dari pandangan bahwa perusahaan melakukan reverse stock split agar saham tidak delisting dari bursa ataupun karena saham kurang laku di pasaran.

\section{REFERENSI}

Adnyani, K. S., \& Putri, I. G. A. M. A. D. (2014). Reaksi Pasar terhadap Pengumuman Reverse Split Pada Perusahaan Go Public di Indonesia. Akuntabilitas, VII(2), 145-152.

Ahn, M. J., Couch, Robert, Wu, W., \& Suharto, Y. (2015). Reverse Stock Splits in The Biotechnology Industry: An Effectuation Approach. Journal of Commercial Biotechnology, 21(1), 3-18. https:/ / doi.org/10.5912/jcb677

Bajra, U., \& Hasani, B. (2012). Event Study on Stock Splits. 0556(1969), 37-43.

Bhattacharya, U., \& Dittmar, A. K. (2005). Costless Versus Costly Signaling In Capital Markets: Theory And Evidence. SSRN Electronic Journal, (November). https:// doi.org/10.2139/ssrn.250049

Bodhanwala, R. J. (2016). Stock Split and Reverse Split-Evidence from India. Great Lakes Herald.

Chung, K. H., \& Pruitt, S. W. (1944). A Simple Approximation of Tobin's Q. Financial Management, 23(3), 70-74.

Crutchley, C. E., \& Swidler, S. (2015). Multiple Reverse Stock Splits (Investors Beware!). Journal of Economics and Finance. https://doi.org/10.1007/s12197013-9259-x

Dewi, K. A. S. (2011). Perbedaan Volume Perdagangan Saham Sebelum dan Sesudah Reverse Stock Split pada Perusahaan yang Terdaftar di BEI Periode 2007-2011.

Dewan Standar Ikatan Akuntansi Indonesia. Peraturan Standar Akuntansi Keuangan Nomor 56 Tahun 2014 Tentang Laba Per Saham. (2014). Indonesia.

Fidhayatin, S. K., \& Uswati Dewi, N. H. (2012). Analisis Nilai Perusahaan, Kinerja Perusahaan dan Kesempatan Bertumbuh Perusahaan Terhadap 
Return Saham pada Perusahaan Manufaktur yang Listing di BEI. The Indonesian Accounting Review, 203. https://doi.org/10.14414/tiar.v2i02.96

Fitria, T. A., Afifudin, \& Junaidi. (2019). Analisis Dampak Reverse Stock Split Terhadap Harga Saham dan Volume Perdagangan Saham. E-JRA, 08(01), 41-53.

Fransiska, L., \& Purwaningsih, A. (2008). Perbedaan Likuiditas Saham Sebelum dan Sesudah Reverse Stock Split (Studi Empiris Pada Bursa Efek Indonesia). 1-23.

Fried, J. M. (2009). Firms Gone Dark. The University of Chicago Law Review, 76(1), $135-160$.

Jing, L. (2003). An Event Study of Reverse Stock Splits in Hong Kong Market. In SSRN. https:// doi.org/10.2139/ssrn.393222

Jog, V., \& Zhu, P. (2004). Thirty Years of Stock Splits, Reverse Stock Splits, and Stock Dividends in Canada. (June), 1-32.

Kontesa, M. (2015). Capital Structure, Profitability , And Firm Value . Whats New? Research Journal of Finance and Accounting, 6(20), 185-192.

Kusdarmawan, P. A., \& Abundanti, N. (2018). Analisis Abnormal Return Saham Sebelum dan Sesudah Reverse Stock Split pada Perusahaan di BEI Periode 2011-2015. E-Jurnal Manajemen Unud, 7(7), 3827-3855.

Marchman, B. (2007). Reverse Stock Splits : Motivations, Effectiveness and Stock Price Reactions. Electronic Theses, Trastises and Dissertations.

Mardiyati, U., \& Khasanah, K. (2011). Studi Komparatif Harga, Likuiditas, dan Risiko Saham Sebelum dan Sesudah Perusahaan Melakukan Stock Split dan Reverse Split di Bursa Efek Indonesia Tahun 2004-2009. Jurnal Riset Manajemen Sains Indonesia (JRMSI), 2(1), 73-94.

Marsha, N., \& Murtaqi, I. (2017). The Effect of Financial Ratios on Firm Value in the Food and Beverage Sector of The IDX. Journal of Business and Management, 6(2), 214-226.

Masse, I., Hanrahan, J. R., \& Kushner, J. (2017). The Effect of Canadian Stock Splits, Stock Dividends, and Revese Splits on the Value of the Firm. Quarterly Journal of Business and Economics, 36(4), 51-62.

Neuhauser, K. L., \& Thompson, T. H. (2014). An Examination of The Survivability of Reverse Stock Splits. International Journal of Managerial Finance, 10(3), 293-311. https:/ / doi.org/10.1108/IJMF-09-2013-0101

Otoritas Jasa Keuangan. Peraturan Otoritas Jasa Keuangan Nomor 29/POJK.04/2016 Tentang Laporan Tahunan Emiten atau Perusahaan Publik. (2016). Indonesia.

Oktavia, Y. (2019). Analisis Perbedaan Abnormal Return dan Likuiditas Perdagangan Saham pada Perusahaan yang Melakukan Reverse Stock Split yang Terdaftar di BEI. Jurnal Akuntansi UNESA. Retrieved from www.investorpialang.com

Panggabean, D., \& Prasetiono. (2017). Analisis Pengaruh Financial Performance, Pengungkapan Corporate Social Responsibility (CSR), Insider Ownership, Firm Size, Dividend Policy dan Proporsi Komisaris Independen terhadap Nilai Perusahaan. Diponegoro Journal of Management, 6(4), 1-12.

Putu, N. N. G. M., Moeljadi, Djumahir, \& Djazuli, A. (2014). Factors Affecting Firms Value of Indonesia Public Manufacturing Firms. International Journal 
of Business and Managent Invention, 3(2), 35-44.

Ratmawati, D., \& Kusumawati, I. D. (2007). Aksi Reverse Split Sebagai Upaya Menjaga Kepercayaan Investor. Majalah Ekonomi, XVII(3), 250-261.

Sanjaya, I. P. S. (2007). Kandungan Informasi pada Pengumuman Reverse Stock Split. Manajemen \& Bisnis, 6, 107-116.

Sudiyatno, B. (2010). Tobin's Q dan Altman Z-Score sebagai Indikator Pengukuran Kinerja Perusahaan. Kajian Akuntansi, 2(1), 9-21.

Vafeas, N. (2001). Reverse Stock Splits and Earnings Performance. Accounting and Business Research. https://doi.org/10.1080/00014788.2001.9729614

Widiastuti, H. (2005). Analisis Faktor-faktor yang Mempengaruhi Stock Split dan Pengaruhnya terhadap Nilai Perusahaan. Jurnal Akuntansi Dan Investasi, 6(1), 206-224. 